\title{
LAS ESTRATEGIAS DEL PODER TRAUMATIZANTE DE UN DICTADOR EN LA FIESTA DEL CHIVO, DE MARIO VARGAS LLOSA
}

\author{
Samuel Manickam
}

\begin{abstract}
RESUMEN
En este artículo se analizarán las estrategias del control totalitario del dictador dominicano Trujillo, retratado en La fiesta del Chivo: él se proyecta como el Padre de la Patria imprescindible mientras que, al mismo tiempo, se empeña en debilitar las estructuras familiares a través de sus violaciones sexuales a mujeres dominicanas. Urania Cabral encarna bien el trauma sexual sufrido por estas víctimas del dictador, y el concepto de "radical injustice" de Brett Levinson ayudará a iluminar el proceso difícil de recuperar de tal trauma en una sociedad posdictatorial.

Palabras clave: trauma, radical injustice, la dictadura.
\end{abstract}

\begin{abstract}
In this article the Dominican dictador Trujillo's strategies of totalitarian control will be analyzed as portrayed in La fiesta del Chivo: he projects himself as the Father of the Nation while at the same time he systematically weakens family structures through his continual sexual violation of Dominican women. Urania Cabral is representative of the trauma suffered by these victims of the dictador, and Brett Levinson's concept of "radical injustice" will help illuminate the difficult process of recovery for these members of a posdictatorial society.

Key words: trauma, radical injustice, dictatorship.
\end{abstract}

Con la publicación de La fiesta del Chivo (2000) Vargas Llosa vuelve a su pasión temprana de escribir la novela total sobre un tema histórico que, en este caso, es la dictadura de Trujillo en la República Dominicana. En esta novela, el autor quiere poner en relieve la extensión y la profundidad de la bajeza moral y la crueldad de este dictador dominicano y

\footnotetext{
Samuel Manickam. Assistant Professor of Spanish. Dept of Foreign Languages \& Literatures. University of North Texas.

Correo electrónico: manickam@unt.edu

Recepción: 14- 5- 2009

Aceptación: 3- 6- 2009
} 
sus muchos colaboradores durante su régimen de tres décadas. La fiesta del chivo expresa el tema predilecto temprano de Vargas Llosa: la corrupción de la inocencia por una autoridad opresiva, visto en sus novelas anteriores como La ciudad y los perros (1963), La casa verde (1966) y Conversación en la Catedral (1969). Aquí el victimario es Trujillo y su víctima es toda la sociedad dominicana.

En este estudio se hará un análisis del poder tiránico de Trujillo para mostrar que este dictador dominicano practica una doble estrategia. Mientras públicamente propaga la ideología de la familia nacional en la cual él queda como el Padre de la Patria, al mismo tiempo fragmenta los lazos familiares con sus innumerables actos de violación sexual en el espacio privado. Aunque se proyecta como un padre necesario para el bienestar del país, se jacta abiertamente de sus muchas conquistas sexuales, con las esposas o las hijas de sus ministros, o cualquier muchacha que le llame la atención. De esta manera, Trujillo acaba debilitando los lazos familiares de los dominicanos para asegurar la perpetuidad de su propio poder. La humillación privada refuerza su poder e imagen públicos y le permite llevar a cabo su empresa de poder total.

Urania Cabral, la protagonista de la novela, encarna bien el trauma sufrido por la República Dominicana; de niña, ella fue violada por Trujillo y, como resultado, buscó refugio en los Estados Unidos, lejos no sólo del dictador sino de su padre, un cómplice en este crimen. A pesar de que logra establecerse como una abogada exitosa en Nueva York, más de treinta años después de que fue violada por Trujillo aún no se ha recuperado. Se verá que ejemplifica lo que Brett Levinson llama "radical injustice", la inhabilidad de la víctima de un dictador/ dictadura por salir del trauma, aunque Levinson agrega que esta situación puede motivar a la víctima a crear un futuro mejor. Así, Urania hace el intento de reconciliarse con su pasado traumático al volver a la República Dominicana para visitar a su padre. El re-encuentro difícil y problemático entre padre e hija. después de tantas décadas, muestra bien la dificultad que cualquier sociedad posdictatorial enfrenta al intentar a regresar a la normalidad.

Frente a los dominicanos, Trujillo propaga el discurso de la familia nacional para fortalecer la ilusión de la unidad del país. Es de notar que entre los muchos títulos que se le dan a Trujillo -el Jefe, el Generalísimo, el Benefactor, Su Excelencia el Doctor Rafael Leonidas Trujillo Molina- el que se usa con más frecuencia en La fiesta del chivo es "Padre de la Patria Nueva" (2000: 15, 119, 127, 141, 460, etc.). El dictador dominicano se considera el progenitor de vida nueva en una república recién nacida. El ministro Cabral dice que aunque los dominicanos tienen miedo del dictador, también llegan "a quererlo, como llegan a querer los hijos a los padres autoritarios, a convencerse de que azotes y castigos son por su bien" (82). David T. Abalos observa que "The politician as a kind of abusive father does not want his children to become mature, critical citizens" (Abalos 1993: xviii). Los sujetos de un dictador paternal pero opresivo se comportan como niños y dejan de cuestionar las acciones de su líder por temor de recibir castigos. Es decir, Trujillo logra infantilizar a sus sujetos -como el ministro Cabral, por ejemplo- para que nunca maduraran políticamente. Respecto a la figura del padre en la obra vargasllosiana, Raymond L. Williams dice que "la imagen militar es de la figura de autoridad que, al fin y al cabo, asociamos con la figura paterna en la obra de Vargas Llosa. Ambas figuras son extremadamente autoritarias, represivas y rígidas" (Williams 1996: 97).

Un personaje en la novela que nunca cuestiona lo que dice y hace este padre es Johnny Abbes García, el encargado del SIM (Servicio de Inteligencia Militar). Él le dice a Trujillo en una ocasión: "Yo vivo por usted. Para usted. Si me permite, soy el perro guardián de usted" (2000: 104). 
Trujillo, astuto y siempre receloso de los elogios, aun de los de un confidente como este, responde: "Si me matan, lo hará alguien muy próximo, un traidor de la familia, digamos" (2000: 104, mi énfasis). Se nota la manera como Trujillo manipula el discurso de la familia nacional cuando sea posible, el pueblo está acostumbrado a creer que él es el padre benévolo de esta familia nacional y no lo que es en realidad: un hombre dispuesto a hacer todo lo posible para mantenerse en el poder; por consiguiente, matarlo sería un acto de traición de sangre, y no un acto de liberación. Aunque sea más por miedo que por convicción, es asombroso observar que el padre de Salvador, uno de los asesinos de Trujillo, aún tiene lealtad inquebrantable hacia el Jefe asesinado. Después de que su hijo fue encarcelado y torturado por el SIM, él critica las acciones de su hijo como "la felonía de un hijo descarriado" (2000: 480), sin importarle el sufrimiento de su hijo al momento de recibir la tortura. En la casa de Salvador el verdadero padre es Trujillo.

Por otra parte, el dictador dominicano intenta crear lazos más perdurables con el pueblo a través de los ritos públicos, como la celebración de su cumpleaños, "el día del Jefe", en que Trujillo invierte millones de pesos en "caramelos, chocolates, juguetes, frutas, vestidos, pantalones, zapatos, pulseras, collares, refrescos, blusas, discos, guayaberas, prendedores, revistas" (2000: 182) para festejar la ocasión. Son fiestas públicas en las cuales este padre generoso reparte regalos y comida a todos los hijos de su familia. Trujillo emplea estos supuestos regalos para consolidar su poder sobre los dominicanos. Respecto al acto de otorgarle regalos al pueblo, Ronald Wintrobe observa lo siguiente:

When dictators make a gift to the public or some part of it, from the public treasury, they are asserting
that it is their right to give that money, and by accepting the gift, the recipient is agreeing to this fact. [...]
By accepting these gifts, the people confirm the dictator's power (Wintrobe 1998: 87).

Con este festival público, los dominicanos acaban legitimizando el poder de Trujillo. Más aun, el dictador aprovecha la ocasión para asistir a los "bautizos colectivos" (2000: 182) donde él es escogido como el compadre de cientos de niños que se volverán sus ahijados; es su modo de establecer un lazo familiar muy fundamental con sus súbditos, a quienes él no conoce en lo personal. Ahora, es bien sabido que la tradición del compadrazgo y, por consiguiente, la familia extendida, es esencial para el funcionamiento de la sociedad latinoamericana. Glen Caudill Dealy considera que

\footnotetext{
[this] collectivity survives as a unit not out of some mystical Catholic traditionalism, but quite simply because it responds to the needs of everyone involved. Kinship and the compadre (godparent) system supply an infrastructure for each participant; they are his or her one constant and "free" aggregation. Others must be earned (Dealy 1992: 178).
}

Se supone que, a través de los compadres y los parientes, un individuo siempre tendrá con quién contar para salir adelante en la sociedad. En este caso, Trujillo es el compadre más solicitado en toda la isla, aunque su motivo verdadero por volverse compadre de miles de dominicanos es más bien maquiavélico, como explica:

Trabar una relación de compadrazgo con un campesino, con un obrero, con un artesano, con un comerciante, era asegurarse la lealtad de ese pobre hombre, de esa pobre mujer, a los que, luego del bautizo, abrazaba y regalaba dos mil pesos (2000: 183).

De este modo calculado, Trujillo va tejiendo la lealtad de los dominicanos con recompensas monetarias.

Si Trujillo es visto como el padre de la república y encabeza la jerarquía de esta familia nacional, entonces es lógico considerar a su esposa, María, como la madre de los dominicanos, 
pero no es el caso. Más bien, es la madre del dictador que disfruta de un lugar elevado en la estimación nacional. Respecto al papel fundamental de las madres en las familias hispanas, Bernardo García nota que, a pesar del papel poderoso del padre en las culturas hispanas, la verdad es que son las madres quienes, al fin de cuentas, tienen más influencia en el desarrollo de los hijos (García 1998: 98). Lo que comenta Alan Riding sobre los hijos varones mexicanos también se puede extrapolar a los hombres hispanos en general: resienten la represión del padre y se alían con sus madres y acaban adorándola como "a long-suffering saintly figure" (Riding 1985: 242). Luego buscan a mujeres maternas para esposas y, al no encontrar a esta mujer idealizada, siguen viendo a sus madres como las mujeres perfectas (Riding 1985: 242). Trujillo también es un macho latinoamericano para quien su madre es la mujer irreprochable, mientras que su esposa es relegada al olvido. Aunque su esposa lleva el título "La Prestante Dama" (2000: 31), el cual quiere decir una mujer sobresaliente, es una designación hueca e hipócrita ya que ella sabe bien que su esposo la desprecia públicamente con sus actos de infidelidad. En cambio, la madre de Trujillo disfruta del título "Mamá Julia, la Excelsa Matrona, progenitora del Benefactor" (2000: 21). Parecida a la Virgen María, santa central del catolicismo, esta madre de la patria también es halagada frecuentemente durante homenajes públicos.

Otra manera como Trujillo fomenta la ilusión de la familia nacional es a través de la creación de supuestos enemigos del pueblo, cuya meta principal es destrozar el estado creado y mantenido por este protector de la patria. El nacionalismo, causa central del dictador, está ligado con combatir a dichos enemigos. Benedict Anderson apunta: "The fact of the matter is that nationalism thinks in terms of historical destinies" (Anderson 1987: 136). Trujillo, en su momento, cree que el destino histórico de la República Dominicana queda en juego por los haitianos que representan el Otro amenazante, y esto requiere atención urgente. En la novela hay alusiones a la masacre de los haitianos en 1937 cuando el Trujillo histórico mandó matar a machetazos miles de ciudadanos del país vecino que vivían y trabajaban en el campo, cerca de la frontera con Haití. El objetivo del dictador era detener la supuesta invasión de su país por los haitianos.

En la novela, Agustín Cabral, ex-ministro de Trujillo, defiende esta acción sangrienta, notando que cuando el Jefe llegó al poder encontró un país "sin ley ni orden, empobrecido, que estaba perdiendo su identidad, invadido por los hambrientos y feroces vecinos" (2000: 16). Cabe notar que Trujillo compara el avance de los haitianos en su país con una enfermedad: "La gangrena había avanzado hasta muy arriba. Montecristi, Santiago, San Juan, Azua, hervían de haitianos. La peste había ido extendiéndose sin que nadie hiciera nada" (2000:235). De acuerdo con Trujillo, el cuerpo dominicano se estaba muriendo por esta invasión de organismos foráneos; había que amputar las partes enfermas para rescatar el resto del cuerpo dominicano. De esta manera, Trujillo se vuelve el salvador que tiene que hacer el trabajo sucio: "Por este país, yo me he manchado de sangre [...] Para que los negros no nos colonizaran otra vez" (2000: 234). Un deber importante del buen dominicano patriota, según Trujillo, es eliminar a los haitianos en su territorio.

Irónicamente, el discurso de la pura sangre dominicana que maneja Trujillo resulta hipócrita cuando se recuerda que la sangre de diferentes grupos raciales se ha mezclado durante los siglos de coexistencia en la misma isla. La familia Trujillo tampoco se escapa de la mezcla con sangre haitiana: la madre de Trujillo es "hija ilegítima de haitianos [...] cuyos rasgos faciales [...] nunca dejó de avergonzarlo [a Trujillo]" (2000: 401). Para disimular su piel morena, todos los días el dictador dominicano "talqueó la cara con prolijidad" (2000: 42). Su rechazo público 
de los haitianos es reflejo de su asco privado al recordar sus propios orígenes haitianos. Esta hipocresía puede ser típica de cualquier líder político que promueve una postura tan xenofóbica; otro ejemplo que evidencia su hipocresía es el uso que hace de una sortija que le había dado "un brujo haitiano, asegurándole que mientras no se la quitara sería invulnerable al enemigo" (2000: 53). Así, mientras públicamente condena a los haitianos, en el ámbito privado es tan supersticioso como aquéllos a quienes critica. El discurso público que fomenta Trujillo a través de palabras, títulos, ritos y acciones sangrientas contra los supuestos enemigos sirve para promover la familia nacional trujillana. Si él es el "Padre de la Patria Nueva" entonces todos los dominicanos son sus hijos y, por extensión, hermanos entre sí; como dice Anderson, "the nation is always conceived as a deep, horizontal comradeship" (Anderson 1987: 16). Sin embargo, la camaradería que quisiera proyectar Trujillo sirve solo un propósito: el mantenimiento de su propio poder.

Aunque en el espacio público el dictador dominicano proclama y promueve una filosofía de la familia nacional, para así fomentar una identidad colectiva, en el espacio privado él insiste en fragmentar los lazos familiares como demostración de quién es el verdadero jefe. Cuando Trujillo se da cuenta del poder de los lazos familiares - "Nada ataba tanto como la sangre, cierto" (2000: 106) - puede estar expresando sus sospechas respecto a la organización familiar y cómo esta puede amenazar su poder dictatorial. Ferdinand Mount observa que "People devote to their families the ardour and effort that ought more properly to be showered on God or nation or community or class" (Mount 1992: 153). ¿Pero por qué Trujillo se puede sentir amenazado por la familia? La respuesta, según Mount, es: "The family's demands are clear and consistent: subsistence, privacy, liberty" (Mount 1992: 176). O sea, la familia puede llegar a ser una unidad independiente si no está controlada y dirigida por el estado; mientras el estado promueve una identidad colectiva, la familia insiste en crear una identidad privada. Añade Mount, "Public goods are supposed to be better, higher, nobler, grander than private goods" (Mount 1992: 165). Ahora bien, la mayoría de las naciones modernas tienen suficientes libertades para que la tensión entre el estado y la familia no se vuelva destructiva, en cambio, en una dictadura -especie de gobierno definido principalmente por el afán de practicar el control total sobre los ciudadanos- la tensión entre el estado y la familia aumentará.

El dictador dominicano no sólo tiene la meta de controlar y humillar a sus enemigos, sino a sus ministros más leales y a sus trabajadores también, para así reafirmar su poder sobre ellos. Peter Elmore nota que para Trujillo "el control del territorio supone también el dominio de los cuerpos" (Elmore 2001: 318). La humillación más impúdica es la libertad que el dictador dominicano practica en acostarse con las esposas de sus ministros, para luego jactarse en público de estas conquistas sexuales. Dealy observa que el jactarse de las conquistas sexuales es un ejercicio común entre los hombres hispanos machistas: "Women are consistently courted before the eyes of peers in order that his triumphs may be acknowledged and his manliness appreciated" (Dealy 1992: 134). Estas mujeres no incluirían ni las esposas ni las novias de los mismos compañeros porque tales conquistas sexuales dejarían en juego la amistad entre los hombres. Trujillo, sin embargo, se siente intocable y por ello se atreve a romper las reglas no escritas de estos ritos machos, lo cual lo convierte en el más macho de todos los hombres. Eve Kosofsky Sedgwick subraya que en cualquier sociedad dominada por los hombres "there is a special relationship between male homosocial [...] desire and the structures for maintaining and transmitting patriarchal power" (Sedgwick 1985: 25). Aunque los lazos homosociales patriarcales existen para consolidar y mantener el poder masculino, Trujillo se atreve a romper estos lazos porque cree que él no los necesita para seguir como un dictador. 
Aunque Trujillo se acuesta con las esposas de sus ministros, tiene preferencia por las muchachas vírgenes. Si se ve al dictador como el padre de esta familia nacional, entonces, por sus frecuentes encuentros sexuales con cientos de dominicanas jóvenes, se puede concluir que él es culpable de cometer simbólicamente el delito de incesto. Jane M. Ford afirma: "Incest eliminates the admission of a stranger into an established bloodline" (1998: 7); es decir, un acto de incesto entre un padre y su hija muestra el carácter propietario del padre respecto a su sangre. El incesto no solo implica que el padre es el único privilegiado que puede iniciar sexualmente a su hija sino el único padre verdadero de los hijos de ella. El padre incestuoso quiere asegurar la perpetuación de su sangre a través de su hijo, que ya es producto parcial de su sangre; es un padre celoso y desconfiado de la sangre de hombres ajenos. La dinámica del incesto da un aspecto siniestro al apetito sexual voraz de este padre, Trujillo, a quien se le tiene que dar "el gusto"; va en contra de un tabú humano antiguo. A la vez, en esta novela se nota el tema vargasllosiano de la inocencia perdida en la violación de tantas dominicanas durante el Trujillato.

Cabe notar que, en la narración de los sucesos de lo que será el último día de Trujillo, éste había tenido relaciones sexuales la noche anterior con una joven y tiene planes para pasar la siguiente noche con otra en su Casa de Caoba donde "acariciaría el cuerpo de una muchacha desnuda, cariñosa, un poco intimidada" (2000: 334). La joven será Yolanda Esterel, de diecisiete años, una muchacha atractiva que él había visto en un desfile donde se le rendía homenaje y que había mandado llegar a la Casa de Caoba esa noche. Con este acto se nota la hipocresía del dictador dominicano: se considera el padrino de miles de niños, pero ahora no ve a esta joven como una posible ahijada, si es que alguna vez tuvo esa visión, sino simplemente como otro cuerpo femenino con quién realizar sus fantasías sexuales.

No se sabe de la reacción de los padres de Yolanda al enterarse de que su hija iba a ser iniciada sexualmente por Trujillo; no obstante, hay más información sobre otra muchacha, Moni, cuyo padre la había llevado a una fiesta diciéndole a Trujillo, "Mire la sorpresa que le traigo" (2000: 419)1. El padre le regala su hija al dictador dominicano no solo para halagarlo sino también para comprobar su lealtad hacia él. Los lazos familiares -sobre todo entre una hija joven e inocente y su padre- se han fragmentado a tal grado bajo Trujillo, que los padres empiezan a ver a sus hijas simplemente como un obsequio para el Jefe y no como su propia sangre que se debe proteger. Como consecuencia de las violaciones frecuentes de Trujillo, dice Lady Rojas-Trempe, "el espacio nacional se [había convertido] en gran prisión, las casas en prostíbulos y las doncellas en presas” (2001: 551). La virginidad de una joven, aspecto físico tradicionalmente vigilado con mucha atención por los padres hispanos, ahora es sacrificada al dictador a cambio de posibles favores en el futuro.

Aunque las muchachas suministradas al Jefe parecen dóciles, la violación sexual a tan temprana edad provoca traumas duraderos y, en esta novela, Urania protagoniza una mujer herida psicológicamente por ser violada por Trujillo y que ahora intenta traer clausura a su trauma. El tema de la inocencia perdida en la novelística de Vargas Llosa se delinea claramente en el personaje de Urania. José Luis Martín, en su excelente estudio sobre las novelas de Vargas Llosa, asevera que

[...] el tema-eje de Vargas Llosa es el individuo víctima de una sociedad ulcerada, o lo que es lo mismo, la sociedad tiranizando al individuo. [Dicho personaje] es inocente -sea al principio o durante toda la obra [y es] traicionado de alguna manera, lo cual acarrea su corrupción, su caída y muchas veces su muerte. La inocencia del personaje le es innata, y esto arrastra nuestra simpatía hacia él. La traición que le corrompe es impartida por la sociedad enferma, representada siempre por un personaje colectivo y simbólico (1974: 83, énfasis del autor). 
En La fiesta del chivo se puede ver cuán enferma es la sociedad dominicana que permite que el dictador -el "personaje colectivo y simbólico"- viole a sus hijas jóvenes e inocentes. La niña Urania tenía fe completa e inocente en su padre, no obstante, este acabó traicionándola al entregarla al Padre de la Patria.

Cabe recordar que aun antes de su encuentro traumático con Trujillo, Urania había crecido con una desventaja: la falta de una madre. La perdió de niña en un accidente automovilístico y, como consecuencia, "quizás la noción de felicidad se evaporó también de la vida de Urania” (2000:23)2. Su padre, Agustín Cabral, nunca se volvió a casar, aparentemente para que pudiera ser tanto padre como madre para su hija (2000: 23). Más tarde, en la novela, el lector se entera de la verdadera razón por el estado soltero de Cabral: "Para dedicar más tiempo al Jefe, consagrarle días y noches, demostrarle que nada ni nadie era más importante en la vida" (2000: 376). Él es representante de los muchos padres durante el Trujillato cuya lealtad principal fue hacia el dictador y no hacia su propia sangre. Por consiguiente, cuando por alguna razón misteriosa Trujillo le da la espalda, Cabral no deja de preguntarse sobre los motivos del Jefe. El hecho de perder el prestigioso puesto de la Presidencia del Senado y que poco después los hombres del SIM empiecen a acosarlo silenciosamente por toda la ciudad es evidencia de que Cabral se había vuelto un sospechoso a los ojos del dictador. No sabe los motivos de su persecución, y nunca sabrá (2000: 282). Un día, Manuel Alfonso, un amigo suyo, lo visita y le lanza una propuesta que, aunque nos parece espeluznante, tiene mucha lógica en el contexto perverso del Trujillato: entregar su hija Urania de catorce años al dictador, como un favor sexual a cambio del perdón. La justificación de Manuel Alfonso muestra el razonamiento torcido que manejan los partidarios del dictador:

\footnotetext{
No pienses sólo en ti, Agustín. No seas egoísta. Piensa en tu muchachita. ¿Qué será de ella si pierdes todo y terminas en la cárcel acusado de malos manejos y defraudación? [...] [Trujillo se] sentirá tocado en el corazón. Te llamará. Te devolverá lo que te han quitado. Uranita tendrá su porvenir seguro. Piensa en ella, Agustín, y sacúdete los prejuicios anticuados. No seas egoísta (2000: 377).
}

En esta sociedad pervertida por un padre incestuoso, el no entregar la hija virgen e inocente al dictador es interpretado como clara evidencia del egoísmo personal. Los "prejuicios anticuados" aquí se refieren al sentimiento protector y de sacrificio que sentiría cualquier padre al ver a su hija en las garras del peligro, el "porvenir seguro" es simplemente lo económico; dentro de la lógica de Alfonso no entra la posibilidad de que la niña pueda quedar psicológicamente dañada después de tal encuentro sexual.

Alfonso logra convencer a Cabral, a pesar de las dudas de este, y Urania asiste la "fiesta del Chivo" con Trujillo. Como observa Lady Rojas-Trempe, "Cabral reduce a su hija a un papel de hembra conciliadora entre dos machos" (2001: 546). La descripción que ofrece Urania de sí junto con la del dictador, en la Casa de Caoba, resulta reveladora: "Lucíamos una pareja muy dispar, subiendo esa escalera con pasamanos de metal y barrotes de madera. De las manos, como novios. El abuelo y la nieta, rumbo a la cámara nupcial" (2000: 555). De nuevo, Trujillo está cometiendo el incesto simbólico. Ahora, muchas jóvenes, como Moni por ejemplo, hacen el esfuerzo de volver a la vida normal -se casan y forman familias- después del forzado encuentro sexual con Trujillo. A pesar de los traumas que seguramente sufrirán, seguirán siendo propiedad del dictador para siempre. No obstante, la reacción de Urania es distinta; en vez de portarse como si no hubiera sucedido nada, para luego cumplir con el rito social del matrimonio, como Moni, busca refugio con las monjas de su escuela que le ayudan a escaparse hacia los Estados Unidos. Al ser traicionada por su padre Urania se niega verlo 
antes de su partida de la isla, a pesar de sus ruegos, y nunca responde a las numerosas cartas que él le escribe a lo largo de los años. El mundo familiar de Urania ha sido derrumbado, y ella experimenta una situación que R.D. Laing describe: "Within the family, the 'family' may be felt as the whole world. To destroy the 'family' may be experienced as worse than murder or more selfish than suicide" (1969: 14). El trauma que experimenta esta joven es tan impactante que jamás quiere ver a su padre, el cómplice de Trujillo en este crimen.

Para entender y analizar mejor la situación de Urania sería útil tomar en cuenta un estado distinto llamado, por Levinson, "radical injustice" situación que se puede hallar en una sociedad posdictatorial en América Latina donde los abusos físicos (la tortura, por ejemplo) y sexuales no encuentran una clara clausura:

\begin{abstract}
Radical injustice [...] emerges not when a crime is committed, and not when the law appears as insufficient and/or erroneous, but when every convention surfaces as obsolete - as pertaining to another time and place - and therefore every act of restitution is impossible. [...] indeed, no convention at all, and thus no punishment at all - exists or can exist: not even an ideal, utopian, or imaginary one (Levinson 2001: 34, énfasis del autor).
\end{abstract}

Al principio de la novela, cuando Urania regresa a la República Dominicana, no ha encontrado ni resolución ni clausura y, por consiguiente, su trayectoria adulta de desarrollo emocional y psicológico se ha quedado estancada. Ella nunca ha podido normalizar sus relaciones con los hombres y vive aterrada, una situación que describe Levinson: "Terror remains present not because events cannot be recalled but because they cannot be absolved" (Levinson 2001: 43). Lo que Cathy Caruth observa sobre los efectos persistentes de una experiencia traumática también se puede aplicar a la situación de Urania: "For those who undergo trauma, it is not only the moment of the event, but of the passing out of it that is traumatic; that survival itself, in other words, can be a crisis" (Caruth 1995: 9, énfasis de la autora).

En el presente Urania cuenta: "Tengo cuarenta y nueve años y, de nuevo, vuelvo a temblar. He estado temblando treinta y cinco años desde ese momento" (2000: 561). Por los comentarios de Levinson y Caruth, parece que Vargas Llosa logra retratar de manera convincente el efecto que el Trujillo histórico tuvo en la vida de sus sujetos: "Trujillo seguía dentro de ellos, vivo aunque el cadáver etaba allí; seguía dominándolos, empequeñeciéndolos desde el interior de su propia personalidad" ("Conversación” 2000: 22).

Si bien se puede decir que la violación sexual que sufrió Urania a manos de Trujillo resultó traumática, al mismo tiempo cabe recordar un detalle fundamental: Trujillo fracasa en el intento de violar a Urania. Por los problemas que el dictador experimenta con su próstata, su miembro sexual queda flácido, símbolo clave de la impotencia masculina; en esta crisis, el dictador parece olvidarse de la niña frente a él porque "Se le escapó un sollozo. Empezó a llorar" (2000: 559). Urania presencia un evento insólito: el Chivo humillado lloriqueando como un niño. La máscara del dictador temible ha sido arrancada. Es muy raro que un dominicano vea al "Jefe" tan debilitado con el símbolo más obvio de su hombría, el falo, puesto en ridículo. Para otra víctima, tal vez este saber secreto y potencialmente dañino sobre un hombre que todo el país teme serviría como un tónico para recuperarse del trauma, pero no es el caso de Urania, una víctima que ha estado "temblando" por décadas.

A pesar de que aún está asustada, en las apariencias, Urania lleva una vida envidiable. Durante sus años en los Estados Unidos, Urania ha estudiado y trabajado sin parar para volverse una abogada exitosa en Nueva York -situación donde no le hace falta ninguna adquisición 
material- y esto debe representar cierta independencia y habilidad para desempeñarse como una mujer liberada que vive en una ciudad sumamente cosmopolita. Irónicamente, a pesar de que ella está colocada dentro del mundo poderoso y tradicionalmente masculino -un bufete jurídico que aboga por corporaciones multinacionales-, no logra hacer nada desde esta posición de poder para salir de su trauma personal; es más, Urania confiesa que el estudiar simplemente fue una manera de escaparse de su trauma: "No era el deseo de aprender, de triunfar, lo que te confinaba en la biblioteca, sino de marearte, intoxicarte, perderte en esas materias [...] para no pensar, para ahuyentar los recuerdos dominicanos" (2000: 215). Y el trabajo de abogada, para ella, no es una pasión sino un escape: "Pero, estoy vacía y llena de miedo, todavía. [...] Trabajar, trabajar, trabajar hasta caer rendida" (2000: 564). Urania no es una mujer moderna que ve su puesto de abogada exitosa como el fin deseado de sus arduos estudios, sino como una fachada inviolable detrás de la cual puede esconder su verdadero ser: una mujer "paralizada con el pasado" (2000: 220).

La violación que Urania experimentó a manos de Trujillo la dejó recelosa de los hombres, nunca más tuvo relaciones sexuales con ningún hombre (2000: 218). Urania le confiesa tristemente a su tía y a sus primas: "Mi único hombre fue Trujillo" (2000:563). Más de tres décadas después de que fue violada por Trujillo, Urania aún odia a los hombres: "Más nunca un hombre me volvió a poner la mano. [...] Cada vez que alguno se acerca, y me mira como mujer, siento asco. Horror. Ganas de que se muera, de matarlo" (2000: 563). Nunca ha logrado normalizar sus relaciones con los hombres. Las primas de Urania descubren que esta abogada exitosa y atractiva nunca ha logrado tener relaciones íntimas con los hombres porque, como confiesa, "A mí, papá y Su Excelencia me volvieron un desierto" (2000: 564). El odio que siente hacia los hombres en general -sobre todo a los que le hacen piropos, como un turista en el hotel en Santo Domingo- la va comiendo poco a poco, provocando una amargura general hacia la vida. Ella nunca ha experimentado una relación amorosa con un hombre; respecto a la falta de amor en la vida de Urania, Gabriela Polit-Dueñas señala:

\footnotetext{
Without libido, no work can get done; without the search for personal satisfaction, no wound can be healed. Without pleasure there is no virtue or fulfilled dream. Without joy, no real recognition can be attained from other human beings. [...] Pleasure is something that we cannot think of in isolation, we always need the other if only through our imagination (Polit-Dueñas 2007: 112).
}

Al volverse recelosa de los hombres, Urania ha eliminado una vía importante: el amor, a través del cual podría empezar a tomar los pasos para salir del laberinto de su trauma. También, ha cortado sus lazos familiares en su país natal durante toda su estancia en los Estados Unidos, a pesar de que sus parientes no tenían la culpa de lo sucedido. A falta del amor y la familia, Urania se ha vuelto una mujer enajenada de la comunidad humana. Por estos detalles fundamentales de la vida adulta de Urania será obvio que, en efecto, ella define bien "radical injustice", situación donde la víctima de los crímenes de una sociedad dictatorial no encuentra ni cura ni clausura.

Por otra parte, cabe recordar que la acción en el presente de la enunciación se centra en el regreso de Urania a la República Dominicana para enfrentar a su padre después de treinta y cinco años de aislamiento en los Estados Unidos. Levinson observa que, a pesar de la situación deprimente donde la víctima de "radical injustice" trae intacto su trauma, al mismo tiempo tal situación puede volverse la herramienta para llegar a cierto futuro más positivo, donde el trauma ya no definirá la vida de la víctima: 


\begin{abstract}
Hence, the limit-experience [radical injustice] stands as the condition of possibility for a (not the but a) new political actor, for novel political organizations after dictatorship, for forgiveness (not the victims' forgiveness of the military but their forgiveness of themselves), and, finally, for the 'ungluing' of the present from the past, a restarting of time: the beginnings of the transition process (Levinson 2001: 52, énfasis del autor).
\end{abstract}

Para la víctima de un dictador, el trauma puede volverse la motivación para comenzar un capítulo nuevo en su vida más allá del dicho trauma. Así, se puede interpretar el viaje que inicia Urania para visitar a su padre, después de tantos años, a pesar de las dudas que ésta aún trae, como el primer paso hacia la recuperación del trauma donde se ha quedado atrapada toda su vida adulta. El hecho de que por fin revela el secreto sucio -la colaboración de su padre en la violación que sufrió-, a sus familiares, le puede aliviar este peso; es decir, al narrar su historia personal y volverse la protagonista de su propia vida, Urania empieza a controlar la narrativa de su vida que ya no debe estar definida por el trauma que provocó Trujillo. Urania no será como tantas otras víctimas femeninas de Trujillo quienes debieron callarse y reprimir sus traumas.

El evento central en el presente de la enunciación en la novela es la reunión entre Urania y su padre. Se supone que al enfrentar a su padre y reconciliarse con él, Urania tomará el primer paso en el presente hacia la recuperación de su trauma de los pasados treinta y cinco años. Sin embargo, es difícil juzgar cuán exitoso fue este encuentro, pues existen problemas que impiden que sea fructífero. En el presente, su padre ya es un anciano senil debido a un derrame cerebral y, como consecuencia, se encuentra "en silla de ruedas, sin andar, hablar, dependiendo de una enfermera para comer, acostarse, vestirse, desvestirse, cortarse las uñas, afeitarse, orinar, defecar" (2000: 15). Este "niño difícil" sólo puede consumir "cosas batidas" (2000: 84) porque le faltan dientes; en su vejez enfermiza, el ministro Cabral se ha vuelto un niño completamente dependiente de la ayuda de otros para seguir viviendo. Es vulnerable y débil, sobre todo porque ha perdido la facultad comunicativa. En efecto, es un mudo; por consiguiente, cuando su hija le hace reclamos sobre sus acciones vergonzosas, el ministro Cabral no puede responder con palabras sino sólo con ruidos incomprensibles. Parece el castigo apropiado para este padre que abandonó a su hija con tal de salvar su reputación frente a Trujillo. Es la situación perfecta y justa cuando Urania por fin puede expresarse libremente sin que su padre la contradiga o la interrumpa para defender y justificar sus acciones.

Urania aprovecha la oportunidad para hacerle preguntas sobre su involucramiento en los crímenes de Trujillo, su pasividad frente a los muchos actos adúlteros del dictador, aun con la madre de Urania, entre otras inquisiciones incómodas; por fin, Urania puede desahogarse después de quedar callada por tantos años. Pero ella no está dialogando con su padre sino que está realizando un monólogo frente a un hombre que -por su debilidad, su vejez y su mudez- es más bien una figura fantasmal. El hombre que Urania ha odiado por tantas décadas se ha vuelto una sombra indefensible, él ya no representa una amenaza para Urania. Esta visión de su padre patético debe ser instrumental en ayudar a Urania a empezar a salir de su trauma. La verdad debe ser , y quizá será, un tónico para su trauma, sin embargo, el resultado inmediato de este encuentro es ambiguo. Cuando su tía le pregunta a Urania por qué aún manda dinero para ayudar a su padre, si está tan enojada con él, responde, "Pero yo no le he perdonado ni lo perdonaré. [...] Prefiero que viva así, muerto en vida, sufriendo [...] Por eso lo ayudo, tía" (2000: 378).

Urania desea que su padre siga vivo para que no acaben sus padecimientos de la vejez y del derrame cerebral. Vivir ya es una tortura para él y ella no quiere que su padre se libere de este castigo merecido. Al mismo tiempo, el ministro Cabral se ha vuelto un mudo y no 
tiene la capacidad física para hablar con su hija y pedirle perdón; es decir, en este encuentro entre padre e hija, por la falta de la posibilidad de un diálogo entre dos seres hablantes y el odio que siente Urania hacia su padre, el trauma que ha sufrido puede quedar intacto. Como ella misma admite: "Pero, nunca habías querido curarte. Por el contrario, no lo consideras una enfermedad, sino un rasgo de tu carácter, como tu inteligencia, tu soledad y tu pasión por el trabajo bien hecho" (2000: 230).

Antes de la reunión con su padre, Urania piensa que ya no lo odia, sin embargo, al verlo de nuevo se da cuenta de que aún lo odia. Respecto a la importancia del perdón como una solución para empezar a salir del trauma causado por una dictadura, Levinson pregunta: "[Is] not the last measure or means by which victims strive to overcome the injustice of the law, not vengeance at all, but forgiveness?", y agrega, "Victims can only forgive by giving up the choice to punish" (Levinson 2001: 46-47). Para el sujeto de un dictador/una dictadura que no encuentra la salida de su trauma -en efecto, que experimenta "radical injustice"- Levinson sugiere que el perdonar es una manera de empezar a encontrar la clausura (Levinson 2001: 52). A pesar de que Urania no encuentra, por ahora, la manera de perdonar a su padre por su crimen reprensible, parece que logra reestablecer los lazos familiares con su tía y sus primas. Se da cuenta de lo importante de la familia: "Sí, sí, ya sé, tienen problemas, apuros, decepciones. Pero también, una familia, una pareja, hijos, parientes, un país. Esas cosas llenan la vida" (2000: 564). Cabe notar que ellas no sólo son sus familiares sino que son mujeres, todas juntas representan una solidaridad femenina que puede empezar a reconstruir la sociedad dominicana destrozada por un terrible dictador que engañaba al pueblo con la máscara del "padre benévolo".

En su ensayo "Family Romances", Sigmund Freud habla de la tarea importante que tiene cada individuo de liberarse de la sombra autoritaria de sus padres. Por más difícil que sea, esta rebelión es esencial para que sea exitoso el desarrollo psicológico personal. Efectivamente, el progreso de la sociedad entera depende de la oposición entre las generaciones sucesivas; por otra parte, agrega Freud, "there is a class of neurotics whose condition is recognizably determined by their having failed at this task" (Freud 1989: 298). A lo largo de la novela, el lector se va dando cuenta de cuán profundo ha sido el trauma de Urania a causa de haber sido violada por Trujillo, parece que ha fracasado en la tarea fundamental de "matar" a su padre simbólico e incestuoso, Trujillo. Al regresar a la República Dominicana, sitio del crimen, para enfrentar a su padre, cómplice de Trujillo, y revelar el secreto sucio a sus familiares, Urania toma el primer paso hacia la salida de este trauma que ha distorsionado su vida adulta. Claro está, nunca se olvidará de lo que Trujillo le hizo aquella noche cuando ella sólo tenía catorce años. La tarea de Urania, sin embargo, es tomar control de esta memoria terrible en vez de dejar que la memoria la domine. Ana Forcinito observa lo siguiente respecto al papel de la memoria en la sociedad posdictatorial en América Latina:

\footnotetext{
La memoria, como campo de batalla de la interpretación histórica y de la proyección del futuro tiene el sello femenino...de la memoria, un devenir que se opone al recuerdo sumiso y que sirve para desterritorializar la memoria, es decir producir una ruptura con el lugar fijo impuesto por el recuerdo oficializado (Forcinito 2004: 19, mi énfasis).
}

Urania ya no desea ser sumisa frente a la memoria de la violación. Al enfrentar a su padre y hacer pública la memoria -al menos con su familia- Urania empieza a exorcizar su trauma radical. Por otra parte, a pesar de que por fin pudo relatar a su tía y a sus primas el secreto sobre su violación y el papel de su padre en lo que fue una traición de sangre, un secreto que ha tenido que ocultar por tantas décadas, al final, Urania aún experimenta dudas: 
“PPor qué lo has hecho? ¿Vas a sentirte distinta, liberada de esos íncubos que te han secado el alma?" (2000:567). Se arrepiente de haberse revelado como una mujer vulnerable acechada por un trauma irreparable; también, al no perdonar a su padre todavía queda ese asunto de familia por resolver, aunque, pensando en sus parientes dominicanos que insisten en mantener sus lazos con ella, Urania se pregunta, “'Tal vez querrá reconstruir de algún modo el vínculo con estos residuos de familia que le quedan?" (2000: 566).

La novela termina con una nota ambivalente; no se sabe qué sucederá con la protagonista después de su regreso a Nueva York y así, Urania se vuelve una representación vívida de las sociedades posdictatoriales, que aún están encontrando, paso a paso, el camino que las lleve hacia un futuro esperanzador.

\section{Notas}

1. Hablando del Trujillo histórico, Vargas Llosa nota que "Algunos, sobre todo entre los humildes, le mostraban al jefe su devoción haciéndole ofrenda de lo que más podían respetar dentro de una cultura machista: la virginidad de sus hijas" (“Conversación entre Vargas Llosa y Enrique Krauze: La seducción del poder" 2000: 25).

2. Con excepción de la madre de Trujillo - la Excelsa Matrona- las madres están ausentes en esta novela. Parece confirmar lo que comenta Debra Castillo de los novelistas del "boom": "In all these works, the maternal body may be a utopian site, but the mother's lack of access to subjectivity is a nonnegotiable given" (Castillo 1992: 23).

\section{Bibliografía}

Abalos, David T. 1993. The Latino Family and the Politics of Transformation. Westport: Praeger.

Anderson, Benedict. 1987. Imagined Communities: Reflections on the Origin and Spread of Nationalism. London: Verso.

Caruth, Cathy. 1995. "Introduction". Trauma: Explorations in Memory. Cathy Caruth (ed.). Baltimore: The Johns Hopkins UP. 3- 12, 151-157.

Castillo, Debra A. 1992. Talking Back: Toward a Latin American Feminist Literary Criticism. Ithaca: Cornell UP.

“Conversación entre Mario Vargas Llosa y Enrique Krauze: La seducción del poder”. 2000. Letras libres. 19 (julio): 22-26.

Dealy, Glen Caudill. 1992. The Latin Americans: Spirit and Ethos. Boulder: Westview Press.

Elmore, Peter. 2001. "Los males del poder y los poderes del mal”. Mario Vargas Llosa: el fuego de la literatura. Tenorio Requejo (ed.). Lima: Arteidea Editores, 317-323. 
Forcinito, Ana. 2004. Memorias y nomadías: géneros y cuerpos en los márgenes del posfeminismo. Santiago: Editorial Cuarto Propio.

Ford, Jane M. 1998. Patriarchy and Incest from Shakespeare to Joyce. Gainesville: UP of Florida.

Freud, Sigmund. 1989. "Family Romances". The Freud Reader. Peter Gay (ed.). New York: W.W. Norton, 297- 300.

García, Bernardo. 1998.The Development of a Latino Gay Identity. New York: Garland Publishing.

Laing, R.D. 1969. The Politics of the Family and Other Essays. New York: Pantheon Books.

Levinson, Brett. 2001. The Ends of Literature: The Latin American "Boom” in the Neoliberal Marketplace. Stanford: Stanford UP.

Martín, José Luis. 1974. La narrativa de Vargas Llosa. Madrid: Editorial Gredos,

Mount, Ferdinand. 1992.The Subversive Family: An Alternative History of Love and Marriage. New York: The Free Press.

Polit-Dueñas, Gabriela. 2007. "Same Old Story: Of Women, Caudillos, and Literature in La fiesta del Chivo". Letras Femeninas. 33 (2) (invierno): 99-119.

Riding, Alan. 1985. Distant Neighbors: A Portrait of the Mexicans. New York:Alfred A. Knopf.

Rojas-Trempe, Lady. 2001. "Violencia político-sexual del Estado, trauma y la historia de una víctima en La fiesta del Chivo". Mario Vargas Llosa: escritor, ensayista, ciudadano y político. Roland Forgues (ed.). Lima: Librería Editorial Minerva Miraflores, 537- 552.

Sedgwick, Eve Kosofsky. 1985.Between Men: English Literature and Male Homosocial Desire. New York: Columbia UP.

Vargas Llosa, Mario. 2003. La fiesta del Chivo. Madrid: Punto de Lectura.

Williams, Raymond Leslie. 2000. Vargas Llosa: Otra historia de un deicidio. México, D.F.: Taurus.

Wintrobe, Ronald. 1998. The political economy of dictatorship. New York: Cambridge UP. 
